Provided for non-commercial research and education use. Not for reproduction, distribution or commercial use.

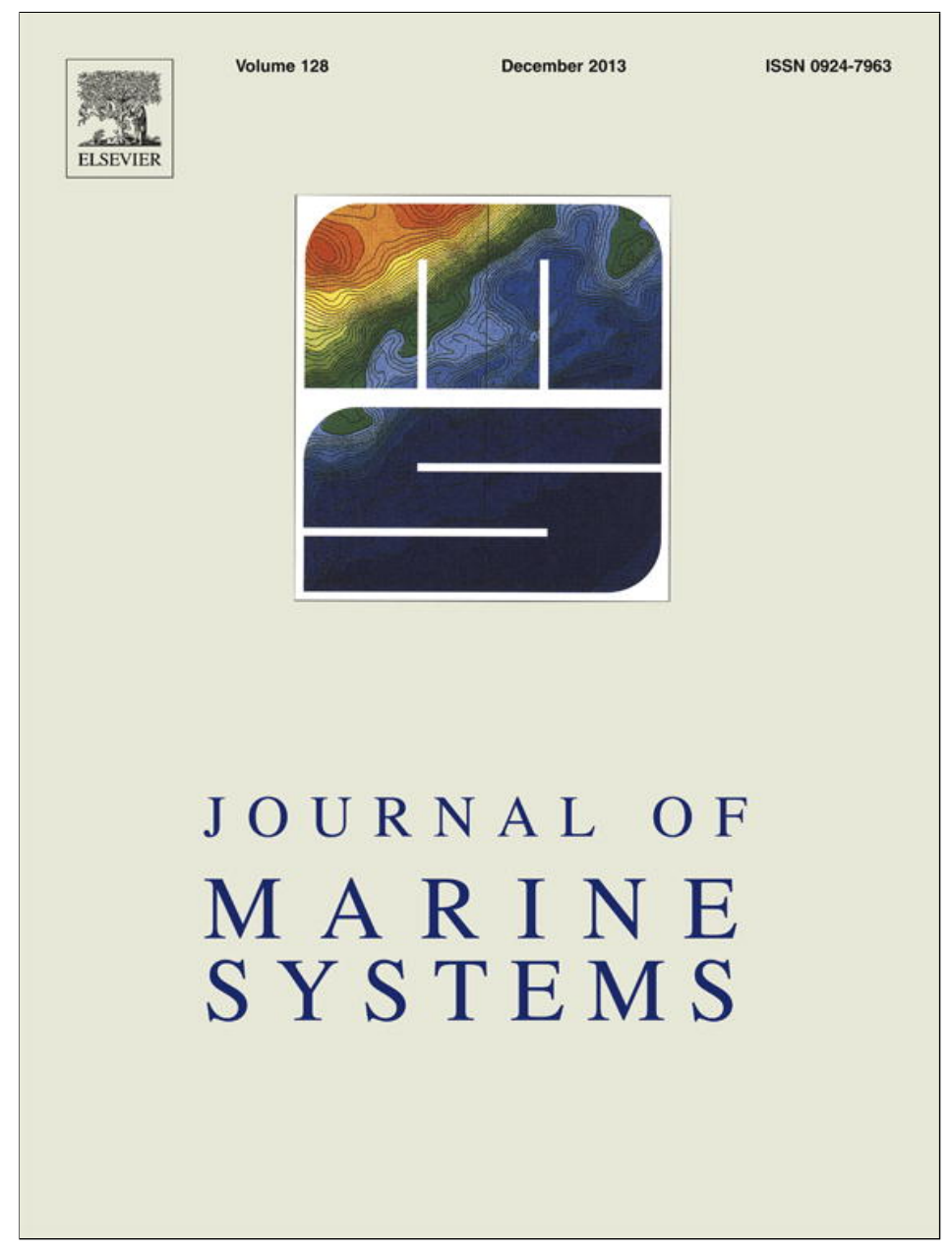

This article appeared in a journal published by Elsevier. The attached copy is furnished to the author for internal non-commercial research and education use, including for instruction at the authors institution and sharing with colleagues.

Other uses, including reproduction and distribution, or selling or licensing copies, or posting to personal, institutional or third party websites are prohibited.

In most cases authors are permitted to post their version of the article (e.g. in Word or Tex form) to their personal website or institutional repository. Authors requiring further information regarding Elsevier's archiving and manuscript policies are encouraged to visit:

http://www.elsevier.com/authorsrights 
Letter to the Editor

\section{All plankton sampling systems underestimate abundance: Response to "Continuous plankton recorder underestimates zooplankton abundance” by J.W. Dippner and M. Krause}

It is axiomatic in plankton research that no plankton sampler, or combination of plankton samplers, can provide a true estimate of abundance for all components of the plankton at anytime. Plankton vary in size from the microbic to large ctenophores and jellyfish, from robust to those extremely fragile and almost impossible to catch without damage. Plankton have extremely diverse behavioural patterns, daily and seasonal vertical migration, and different feeding, reproductive, survival and escape strategies. Even within the crustacean mesozooplankton abundances vary in four dimensions. Consequently, it has been necessary to develop numerous different types of sampling systems, and different mesh sizes have been used, in order to capture or observe the various components of plankton. Wiebe and Benfield (2003) listed more than 200 systems and that is not exhaustive. All systems underestimate parts of or all the plankton leading researchers to choose the system most suited to their study.

There has always been a desire to understand the differences between each system and to quantify the degree of underestimation. Differences in sampling protocols and nets have made it difficult for large-scale comparisons of plankton abundance and biomass. This issue has become more important as the demand grows for accurate estimates of plankton abundance for estimating productivity and applying biogeochemical, food web and marine ecosystem models. We cannot accurately measure true plankton abundance in the water with certainty against which we can calculate the error of an estimate from a net sample. At best, we are left with comparing one system against another to record the differences, but such comparisons must be conducted in an extensive systematic manner under the same conditions (see Skjodal et al., 2013), and recognising that the systems being compared each have their own deficiencies. This is where there is a serious flaw with the paper by Dippner and Krause (2013). They compared the Continuous Plankton Recorder with $270 \mu \mathrm{m}$ mesh towed horizontally, with a Messhai and WP-2 nets both fitted with $200 \mu \mathrm{m}$ and towed obliquely and vertically, respectively, and over just 43 days in late winter. The authors sought to estimate the relative error of CPR measurements, which is appropriate, but failed to provide an assessment, or at least acknowledge, the errors of the two nets. The unspecified bars for the WP-2 net in Fig. 2 of Dippner and Krause (2013) suggest that the errors are likely to be large. This raises the question of what were the differences in abundance estimates between the two nets? Consequently it was disingenuous to single out the CPR as underestimating abundance, and thus not suitable for ecosystem models, when the deficiencies of the nets were not acknowledged nor any justification given that the abundance estimates from the plankton nets are necessarily better for ecosystem models. The true value and purpose of the CPR were also not duly recognised. In fact, CPR data have been used successfully in various ecosystem models. For example, Buitenhuis et al. (2006) used both CPR data and plankton net data to include an explicit representation of mesozooplankton in the PISCES global biogeochemical model. CPR data have been used in bioregionalisation modelling (Pinkerton et al., 2010), as well as network analysis to better visualise zooplankton community structure and these were found to be in good agreement with previously published results (Raymond and Hosie, 2009).

The CPR is unique in having a consistent design and methodology that has remained relatively unchanged for eight decades. Further, it can be towed from any vessel at a depth of $\sim 10 \mathrm{~m}$ at normal cruising speed (hence there is no cost to ship time), and in nearly any weather or sea state. The water and plankton enter a small aperture of $12.7 \times 12.7 \mathrm{~mm}$, which then expands into a tunnel of the filtering area of $100 \times 50 \mathrm{~mm}$. This results in an estimated 1/30 reduction in flow rate across the mesh (Batten et al., 2003). At 15 knots that would equate with a tow speed of about 0.5 knots or $0.25 \mathrm{~m} \mathrm{~s}^{-1}$ through the mesh. This is considerably less than a plankton net hauled at 2 knots. Such low flow rates have been confirmed by the flow volumes recorded on the CPR (Walne et al., 1998). The CPR has proved to be a cost-effective consistent sampling method for rapidly and repeatedly surveying plankton diversity over ocean basin scales. It has provided sustained long-term observations of interannual changes in plankton populations and communities, as well as seasonal patterns of abundance and distribution, and phenological shifts. The programme has found species new to science (Navicula planamembranacea) and has enabled the detection of species introduction and invasion (e.g. Neodenticula seminae in the North-west Atlantic or Coscinodiscus wailesii in the North Sea, Edwards et al., 2001). However, the CPR is not perfect. We know it underestimates components of the plankton, e.g. large plankton like euphausiids, delicate gelatinous plankton, and plankton smaller than the $270 \mu \mathrm{m}$ mesh. This has been well documented, and users of the data are advised of the CPR's limitations, and help is offered in interpreting the data.

Two notable papers by Clark et al. (2001) and John et al. (2001) previously compared abundance estimates of the WP-2 net $(200 \mu \mathrm{m})$ with the CPR data, for a variety of taxa of varying size. These studies attempted to understand the differences between the sampling gear and hence better estimate differences in selectivity and quantitative accuracy so that CPR data could be adjusted and used for modelling. These comparisons were conducted over long time periods of 27 and 11 years respectively, providing both long-term inter-annual comparison and multiple seasonal comparisons. A comparison over 43 days is too short to understand either inter-annual or seasonal variation and thus runs the risk of being affected by seasonal temporal variation. Unsurprisingly, both Clark et al. (2001) and John et al. (2001) reported that the $200 \mu \mathrm{m}$ mesh caught substantially more plankton than the CPR $270 \mu \mathrm{m}$ mesh. However, both studies showed that long-term and seasonal cycles in the CPR data were significantly similar to the data collected by the WP-2, and hence the CPR was suitable for studying long-term and seasonal plankton trends. 
Dippner and Krause (2013) missed a crucial paper in their comparison of CPR data with other nets. Hunt and Hosie (2003) compared CPR data against data collected by a Norpac net along the same sampling track with both systems fitted with the same $270 \mu \mathrm{m}$ mesh. It was a like-versus-like comparison to avoid the issue of different mesh sizes and thus determine any difference due to design and methodology. Vertical Norpac net samples were collected at 19 stations in four stratified layers $(0-20,20-50,50-100,100-150 \mathrm{~m})$ on a southward run along $\sim 140^{\circ} \mathrm{E}$ in the Southern Ocean between 47 and $61^{\circ} \mathrm{S}$ in $9-22$ November 2001. CPR tows were conducted on the return northward run along the same transect in 7-11 December 2001. The 0-20 m Norpac sampling layer was specifically chosen to correspond with the CPR sampling depth. Dippner and Krause (2013) also compared the CPR data against data from the uppermost plankton net of the Messhai, but did not specify the actual depth. Despite the differences in timing the CPR produced abundances comparable to those from the 0 to $20 \mathrm{~m}$ Norpac net, with similar species composition. Specifically, for 22 of the 30 taxa compared there were no significant differences in abundance, five were slightly higher in the Norpac net and three taxa, Oithona similis, appendicularians and nauplii of Rhincalanus gigas had substantially higher abundances in the CPR than the Norpac net resulting in the CPR catching more plankton overall. The higher abundances in the CPR may have been due to the time difference between the Norpac and the CPR sampling, but overall the two systems using the same $270 \mu \mathrm{m}$ mesh produced similar abundances. Similarly, Skjodal et al. (2013) confirmed that different net systems fitted with the same mesh produce similar abundance estimates. This suggests that the design of the CPR and its method of sampling are not a major source of underestimation in abundances relative to different mesh sizes.

It needs noting that both Clark et al. (2001) and John et al. (2001) concluded that the difference in mesh size in their WP-2/CPR comparison could only partially explain the differences in abundance and that differences in the behaviour of individual taxa could cause additional variation in abundance estimates. Diel vertical migration is one important factor and hence the importance of the need to conduct comparisons under the same conditions. Dippner and Krause (2013) referred often to the underestimate of 0 . similis, but noted that vertical migration by this species is weak. 0 . similis is by far the numerically dominant species in the Southern Ocean CPR samples, often reaching $50 \%$ of the total number (Hunt and Hosie, 2003). It exhibits very strong diel vertical migration.

Dippner and Krause (2013) presented three open questions.

1. That increasing ship speed will increase both the pressure of water across the mesh pushing more plankton through and increased head pressure (bow wave) leading to early avoidance by plankton. Both are difficult to assess, but are also unlikely. The CPR is towed within the ship's propeller wash, i.e. in turbulent water. Assuming the CPR is being towed normally at a distance of about $100 \mathrm{~m}$ behind the ship at a depth of $10 \mathrm{~m}$ and at a speed of 15 knots, then plankton have about $13 \mathrm{~s}$ after passing the propeller to re-orientate themselves, detect and avoid the CPR, while still in turbulent water. In relation to water pressure across the mesh, it has been noted above that the water flow reduces by about $1 / 30$ producing a water flow across the collecting mesh much lower than a standard plankton haul. Some vessels towing CPRs travel at 23 knots. Even at that speed the flow rate across the mesh is estimated as $0.39 \mathrm{~ms}^{-1}$ or 0.77 knots.

2. Environmental conditions may affect the vertical distribution of plankton. This is probably true but could such changes in environmental conditions possibly influence the vertical distribution of plankton to any greater degree than that which already takes place via seasonal and diel vertical migration? Further, any changes in vertical distribution will also affect other nets towed obliquely (e.g. the Messhai) or even vertical hauls through a narrow depth range, not just the CPR. The CPR does sample a well mixed surface layer through the action of the ship's propeller. Neuston are also recorded. Hunt and Hosie (2003) showed that while abundances and diversity change with depth in the Norpac samples the CPR samples were still reasonably indicative of species composition deeper in the water, primarily due to DVM.

3. Increasing temperature will lead to decreased body size, shift in community size structure and hence reduce the catch efficiency. Any reduction in the body size of plankton will result in reduced catch efficiency and this applies not just to the CPR but to any sampling system. The North Atlantic CPR Survey has in fact observed a decrease in the mean community size of copepods paralleling an increase in plankton biodiversity, which co-occurred with temperature warming (Beaugrand et al., 2010). This phenomenon of dwarfism is however unlikely to have significantly affected catch efficiency. Nonetheless, in relation to long-term sustained monitoring such a change in catch efficiency, and hence decrease in numbers, is an important trend that needs to be monitored and reported. The CPR is well placed to make such observations, seasonally and inter-annually.

\section{Concluding remarks}

We agree with Dippner and Krause (2013) that in order to properly understand plankton dynamics several different sampling methods are required. We return to our opening statement that no single plankton system can accurately sample all the plankton. We also agree that an intense comparison of sampling systems is required, but it must be systematic, extensive and conducted under the same conditions. Comparing samplers based on different mesh sizes as done by Dippner and Krause (2013) will also trivially lead to the conclusion that the sampler based on the bigger mesh size under samples plankton. The effects of different mesh sizes need to be considered as well using the same mesh on different systems to determine any differences due to mechanical design. Skjodal et al. (2013) is an important recent addition to this work and needs expanding. However, the study also demonstrated that significant resources and ship time are required for such an exercise and this is increasingly harder to fund.

We do not agree with Dippner and Krause (2013) in their conclusion that the CPR is unsuitable for modelling ecosystem dynamics, as we contend that all plankton sampling systems underestimate abundance of some or all taxa in a sample. As noted above, more comparative analysis is required, but an internally consistent time series like the CPR is always useful for the development of models because the errors of uncertainty are constant in an unchanging sampling method. For many decades, the CPR survey has sampled the marine epipelagic zone on a monthly basis over vast spatial areas in a consistent way. Coupled with this are the stringent quality assurance procedures applied to the acquisition of the CPR data. If the CPR underestimates the abundances by a factor of 25 compared with a $200 \mu \mathrm{m}$ mesh net, then how much does the $200 \mu \mathrm{m}$ mesh net underestimate? What nets are acceptable for providing data for ecosystem models?

\section{References}

Batten, S.D., Clark, R., Flinkman, J., Hays, G., John, E., John, A.W.G., Jonas, T., Lindley, J.A., Stevens, D.P., Walne, A., 2003. CPR sampling: the technical background, materials and methods, consistency and comparability. Prog. Oceanogr. 58, 193-215.

Beaugrand, G., Edwards, M., Legendre, L., 2010. Marine biodiversity, ecosystem functioning, and carbon cycles. PNAS 107, 10120-10124.

Buitenhuis, E., Le Quéré, C., Aumont, O., Beaugrand, G., Bunker, A., Hirst, A., Ikeda, T. O'Brien, T., Piontkovski, S., Straile, D., 2006. Biogeochemical fluxes through mesozooplankton. Global Biogeochem. Cycles 20, GB2003. http://dx.doi.org/ 10.1029/2005GB002511.

Clark, R.A., Frid, C.L.J., Batten, S., 2001. A critical comparison of two long-term zooplankton time series from the central west North Sea. J. Plankton Res. 23, 27-39. Dippner, J.W., Krause, M., 2013. Continuous plankton recorder underestimates zooplankton abundance. J. Mar. Syst. 111-112, 263-268. 
Edwards, M., John, A.W.G., Johns, D.G., Reid, P.C., 2001. Case history and persistence of the non-indigenous diatom Coscinodiscus wailesii in the north-east Atlantic. J. Mar. Biol. Assoc. U. K. 81, 207-211.

Hunt, B.P.V., Hosie, G.W., 2003. The Continuous Plankton Recorder in the Southern Ocean: a comparative analysis of zooplankton communities sampled by the CPR and vertical net hauls along $140^{\circ} \mathrm{E}$. J. Plankton Res. 25 (12), 1-19.

John, E.H., Batten, S.D., Harris, R.P., Hays, G.C., 2001. Comparison between zooplankton data collected by the Continuous Plankton Recorder survey in the English Channe and by WP-2 nets at station L4, Plymouth (UK). J. Sea Res. 46, 223-232.

Pinkerton, M. Smith, A.N., Raymond, B. Hosie, G.W. Sharp, B, Leathwick, J.R. Bradford-Grieve, J.M., 2010. Spatial and seasonal distribution of adult Oithona similis in the Southern Ocean: predictions using boosted regression trees. Deep-Sea Res. I 57, 469-485.

Raymond, B., Hosie, G., 2009. Network-based exploration and visualisation of ecological data. Ecol. Model. 220, 673-683.

Skjodal, H.R., Wiebe, P.H., Postel, L., Knutsen, T., Kaartvedt, S., Sameoto, D.D., 2013 Intercomparison of zooplankton (net) sampling systems: results from the ICES GLOBEC sea-going workshop. Prog. Oceanogr. 108, 1-42.

Walne, A.W., Hays, G.C., Adams, P.R., 1998. Measuring the filtration efficiency of the Continuous Plankton Recorder. J. Plankton Res. 20, 1963-1969.

Wiebe, P.H., Benfield, M.C., 2003. From the Hensen net toward four-dimensional biological oceanography. Prog. Oceanogr. 56, 7-136.

N.J.P. Owens

Sir Alister Hardy Foundation for Ocean Science, Plymouth, UK

G.W. Hosie

SCAR Southern Ocean CPR Survey, c/- Australian Antarctic Division,

Hobart, Australia

Chair of the Global Alliance of CPR Surveys, C/- SAHFOS, UK Corresponding author at: SCAR Southern Ocean CPR Survey, c/- Australian Antarctic Division, Hobart, Australia. Tel.: +61362323364.

E-mail address: graham.hosie@aad.gov.au.
S.D. Batten North Pacific CPR Survey, SAHFOS, Canada

M. Edwards

D.G. Johns

SAHFOS, Plymouth, UK

G. Beaugrand

Laboratoired'Océanologie et de Géosciences' CNRS 8187,

Wimereux, France

2 May 2013 